\title{
How new strategies can improve productivity in crystallization and cryoEM
}

Patrick Shaw Stewart, Douglas Instruments Ltd, Hungerford, UK

Abstract

Random Microseed Matrix-Screening (rMMS), where seed crystals are added automatically to random crystallization screens, is a significant recent breakthrough in protein crystallization [1]. During the ten years since the method was published, understanding of the theoretical advantages of the method has increased [2 - 4], and several important practical variations on the basic method have emerged. Important variations that will be discussed include combining seeds from several hits [5], the best methods of selecting hits to optimize [2], and cross-seeding targets with crystals of homologous proteins [6]. I will also present an approach that allows the method to be applied to the crystallization of membrane proteins in LCP [7], and a novel approach to preparing samples for cryoEM using "in situ" dynamic light scattering. This will include discussion of the composition of the ideal screen for cryoEM.

[1] D'Arcy, Allan, Frederic Villard, and May Marsh. "An automated microseed matrix-screening method for protein crystallization." Acta Crystallographica Section D: Biological Crystallography 63.4 (2007): 550-554.

[2] Shaw Stewart, Patrick D., et al. "Random microseeding: a theoretical and practical exploration of seed stability and seeding techniques for successful protein crystallization." Crystal Growth \& Design 11.8 (2011): 3432-3441.

[3] D'Arcy, A., Bergfors, T., Cowan-Jacob, S. W., \& Marsh, M. (2014). Microseed matrix screening for optimization in protein crystallization: what have we learned?. Acta Crystallographica Section F: Structural Biology Communications, 70(9), 1117-1126.

[4] Shaw Stewart, P., \& Mueller-Dieckmann, J. (2014). Automation in biological crystallization. Acta Crystallographica Section F: Structural Biology Communications, 70(6), 686-696.

[5] Obmolova, G., Malia, T. J., Teplyakov, A., Sweet, R. W., \& Gilliland, G. L. (2014). Protein crystallization with microseed matrix screening: application to human germline antibody Fabs. Structural Biology and Crystallization Communications, 70(8).

[6] Abuhammad, Areej, et al. "Structure of arylamine N-acetyltransferase from Mycobacterium tuberculosis determined by cross-seeding with the homologous protein from M. marinum: triumph over adversity." Acta Crystallographica Section D: Biological Crystallography 69.8 (2013): 1433-1446.

[7] Kolek, S. A., Bräuning, B., \& Shaw Stewart, P. D. (2016). A novel microseeding method for the crystallization of membrane proteins in lipidic cubic phase. Acta Crystallographica Section F: Structural Biology Communications, 72(4), 307-312. 